\title{
EFFECTS OF ORAL INGESTION OF HYOSCYAMINE FROMDaturastramonium SEEDS ON THE HIPPOCAMPUS IN ADULT WISTAR RATS (Rattusnorvegicus)
}

\author{
Idris, A. T., ${ }^{1 *}$ Sunday, A. M., ${ }^{2}$ Ibrahim, A. I., ${ }^{3}$ James, 0. N., ${ }^{4}$ Musa, A. K., ${ }^{1}$ and \\ Abdullahi, G. ${ }^{1}$ \\ ${ }^{1}$ Department of Anatomy, Faculty of Basic Medical Sciences, College of Health Science, Bayero University Kano, \\ Nigeria. \\ ${ }^{2}$ Department of Human Anatomy, Faculty of Basic Medical Sciences, College of Medical Science, Ahmadu Bello \\ University Zaria, Kaduna State, Nigeria. \\ ${ }^{3}$ Department of Human Anatomy, Faculty of Basic Medical Sciences, College of Medical Science, Federal \\ University, Dutse, Jigawa State, Nigeria. \\ ${ }^{4}$ Department of Veterinary Anatomy, Faculty of Veterinary Medicine, Ahmadu Bello University Zaria, Kaduna \\ State, Nigeria. \\ *Corresponding author: gwtel4u@gmail.com
}

\begin{abstract}
The study aimed to evaluate the effects of oral ingestion of hyoscyamine fraction of Daturastramonium seeds on the hippocampus in adult Wistar rats. Fresh seeds of $D$. stramonium were procured and fractionated using high-performance liquid chromatography (HPLC). Twenty-four healthy adult Wistar rats weighed $230 \pm 0.50$ grams, were procured and divided equally into four groups for the experiment. The group one received an equivalent bodyweight of normal saline, while three other groups received 200, 400 and $800 \mathrm{mg} / \mathrm{kgbwt}$ of hyoscyamine fraction of D. stramonium respectively for three weeks. At the end of the experiment, the animals were subjected to memory test using Morris water maze (MWM) and Novel object recognition test (NORT) test paradigms. The data obtained were expressed as mean \pm SEM and repeated measures ANOVA with Fisher's mu/tiple comparisons post-hoc tests were used to obtain mean differences using Minitab 17 (LLC., U.K.) statistical package software. $P<0.05$ was considered statistically significant. There was a statistically significant increase in the exploration time $(p=0.031)$ and escape latency period $(p<0.001)$ in the novel object recognition and Morris water maze test between the groups in the treated compared to the control group. The CA3 region of the treated group showed significant neuronal lesions, cytoplasmic vacuolations, pyknosis and necrosis. In conclusion, exposure to hyoscyamine fraction of $D$. stramonium at adulthood impaired memory in Wistar rats. Keywords: Daturastramonium, hippocampus, hyoscyamine, learning, memory.
\end{abstract}

\section{INTRODUCTION}

Daturastramonium is a hallucinogenic plant that belongs to the Solanaceae family. It has potential medicinal values owing to its pharmacological properties. Some of these values include anti-inflammatory, anticholinergic, antihistaminic, acaricidal, antimicrobial, and anticancer activities (Soniet al., 2012). It was also reported to be used in the treatment of depression, madness and epilepsy (Mueseret al., 1998). Although all parts of $D$. stramonium are toxic, its ripened seeds contain the highest concentration of its active principles (Miraldiet al., 2001; Joshia and Prakashb, 2015; Benouadahet al., 2016; Jonasson and Afshari, 2016; Mishra, 2018). The active principles include scopolamine, atropine and other alkaloids which are classified as deliriants, or anticholinergics (Dikeret al., 2007). Its frequent poisoning may be linked to its ubiquitous nature, ease of contaminating foodstuffs and potable water and its high toxicity (Kurzbaumet al., 2001; Oberndorferet al., 2002; Aroukoet al., 2003; Steenkamp et al., 2004; Al-Shaikh and Sablay, 2005; Boumbaet al., 2005; Ertekinet al., 2005; Forrester, 2006; Montcriolet al., 2007; Dubey and Sanjeev, 2017; Trancăet al., 2017; Başaranet al., 2018; Korkmazet al., 2019). Overdose of $D$. stramonium produces a classic anticholinergic syndrome which leads to severe and fatal complications (Melvin and Hourani, 2014). Intoxication typically produces both central and peripheral symptoms which include; delirium, hyperthermia, tachycardia, bizarre behaviour, and severe mydriasis with resultant painful photophobia that can last several days(Roblot, 1995; Vearrier and Greenberg, 2010). Regardless of the part ingested, $D$. 
BAJOPAS Volume 13 Number 2,December, 2020

stramonium may cause complications whose diagnosis may be difficult to unravel (Dikeret al., 2007; Jonasson and Afshari, 2016; Uddin et al., 2017). Several cases of suicide and murder in India and Europe have been traced to Daturastramonium, hence, strict legislation prohibiting its cultivation has been implemented in several places (Preissel and Hans-George, 2002; Bontoyan, 2010; Jonasson and Afshari, 2016; Mishra, 2018).

Hippocampus is an extension of temporal part of the cerebral cortex (Gilbert and Brushfield, 2009) which is essential for the rapid formation and consolidation of memories into in the neocortex (Corkin, 1984; Milner et al., 1998; Squire and Alvarez, 1995). Therefore, stress or chemical substances can damage the hippocampus.

In Nigeria, Daturastramonium is intentionally abused by the youth for recreational purposes or accidentally ingested as food contaminant following the harvest of farm produce. This leads to several cases of medical emergencies and health problems which sometimes results in death. Despite the widely reported toxicity of the plant, literature is scanty on the role of repeated abuse of the toxic phytoconstituents such as hyoscyamine fraction of $D$. stramonium on the hippocampus. Hence, the present study aimed to evaluate the effects of hyoscyamine fraction of D.stramonium seeds on the hippocampus of in adult Wistar rats. The study may serve as a tool to strengthen the existing legislation governing the prohibition of drugs and substances abuse.

\section{MATERIALS AND METHODS}

\section{Plant Materials, Extraction and Fractionation}

Ethical approval was obtained from the Ahmadu Bello University Committee on Animal Use and Care(ABUCAUC/2018/042). Fresh D. stramoniumseedswere procured from Sharada residential area of Kano Municipal Local Government, Kano State, Nigeria. The seeds were identified and a voucher number (VN108) was issued at the herbarium of the Botany Department, Faculty of Life Sciences, Ahmadu Bello University, Zaria, Kaduna state, Nigeria. The seeds were extracted and partitionfractioned according to Kamadaet al. (1986) and Djilaniet al., (2006). Two thousand grams of the dried seeds were weighed using a digital weighing machine, grounded to a pulp using an electronic blender. The pulverized seeds powder was cold macerated with $70 \%$ ethanol and fractioned with a $5 \mathrm{ml}$ portion of $10 \%$ sulphuric acid $\left(\mathrm{H}_{2} \mathrm{SO}_{4}\right)$. The quantity of the fraction was obtained by the high-performance liquid chromatography (HPLC). All analyses were carried out at the Department of Pharmaceutical Chemistry, Faculty of Pharmaceutical Sciences, Ahmadu Bello University Zaria.

\section{Experimental Animals and Design}

Forty (40) healthy adolescent Wistar rats at postnatal day (PND) 21-42 comprised of equal genders were procured from the Animal House of the Anatomy Department, Faculty of Basic Medical Sciences, Bayero University Kano. The animals were housed and allowed to acclimatize for two weeks at ambient temperature, with alternate day and night cycles natural condition at the Department of Pharmacology and Therapeutics, Faculty of Pharmaceutical Sciences, Ahmadu Bello University Zaria. Rat chow ( Vital feeds ${ }^{\mathbb{R}}$ ) and tap water were made available to the animal'sad libitum. The median lethal dose $\left(L D_{50}\right)$ of hyoscyamine fraction was determined using Lorke's (1983) method. The animals were randomly selected and divided into four. The first group received a single daily dose of equivalent bodyweight of normal saline, while the remaining groups received 200, 400 and 800 $\mathrm{mg} / \mathrm{kgbwt}$ of hyoscyamine fraction of $D$. stramoniumseeds as control and treated groups respectively orally for three weeks. All the procedures carried out were in concert with the approval of Ahmadu Bello University (ABU) Zaria Animal's Right and Ethics Committee for Scientific Research Purposes.

\section{Novel Object Recognition Test}

This was to test short-term memory after administration of the hyoscyamine fraction of the $D$. stramonium seeds. The test consisted of three phases i.e. (habituation, sampling and test) which was completed in two days. For each phase of this test, the open field arena was thoroughly cleaned with an unscented bleach germicidal wipe, $70 \%$ Ethanol followed by distilled water before initial use. A day before object exposure, the rats were habituated to the open field arena in a $50 \times 50 \mathrm{~cm}$ wooden box. Before habituation session, a SONY ${ }^{\circledR}$ (Model DCR - PJ5E) digital and a video camera was used for a proper video covering of the rats in the maze. A rat at a time was gently removed from the home cage and placed in the centre of the arena. The video covering system was turned on and the rat was allowed to freely explore the arena for 10 minutes. At the end of every session, the arena was thoroughly sanitized before the next session began. This was repeated for all the rats until all got habituated the arena. The same protocol was observed during the sampling and test phases only that, two identical objects $\left(A_{1}\right.$ and $\left.A_{2}\right)$ were used and two unidentical objects ( $A$ and $B$ ) objects were used for 15 minutes respectively. 
BAJOPAS Volume 13 Number 2,December, 2020 Morris Water Maze

The aim was to test spatial learning and memory after administration of the hyoscyamine fraction of the $D$. stramonium seeds. This was carried out for six consecutive days using a modified Morris method (1984). The apparatus consisted of a circular Aluminium tank of $100 \mathrm{~cm}$ diameter and $60 \mathrm{~cm}$ depth with an escape platform of 20 $\mathrm{cm}$ long and $12 \mathrm{~cm}$ diameter, filled with a pool of clean water of about two-third of the tank at $22-25^{\circ} \mathrm{C}$, deep enough to expose $2.54 \mathrm{~cm}$ (1 inch) of the platform above the water surface. A digital video device, SONY ${ }^{\circledR}$ (Model DCR - PJ5E) was suspended directly over the pool to capture the entire setup. The rats were trained for 5 days with methylene-blue coloured water that submerged the platform about 1 inch under. A latency period of $60 \mathrm{sec}$ was allowed for each to find the platform. This was repeated for all the rats at five different locations by changing the positions of the platform in the pool within the $\mathrm{N}, \mathrm{E}, \mathrm{S}$, and $\mathrm{W}$ directions following Qing et al.(2008) protocol. The same protocol was observed during the test day 6 , however, 30 seconds for trial and the escape platform was removed. The time taken for each rat to identify the usual position of the platform was recorded and while all videos recorded for the trials were analyzed for the escape latency.

\section{Animal Sacrifice and Tissue Preparation}

The animals were euthanized using $75 \%$ Ketamine (10 mg/ml USP) anaesthesia, the brains were dissected, removed and fixed in Bouin's fluid. The tissues were processed in the Department of Pathology, Ahmadu Bello University Teaching Hospital (ABUTH), Shika, Zaria, Kaduna state, Nigeria. The brain tissues were dehydrated in different grades of alcohol and cleared in xylene using an automatic processing machine (Shandon Southern Duplex Processor). The tissues were then infiltrated with paraffin wax and blocked in the coronal plane. Serial sections of the blocks were taken at $8 \mu \mathrm{m}$ with a (LeitzWetzlar) microtome, mounted on glass slides and allowed to dry overnight. The staining technique employed was hematoxylin and eosin in paraffin sections (Lillie and Fullmer, 1976). Sections were then observed under a light Olympus Binocular Microscope (Ch-20i, Uttar Pradesh, India) high magnifications ( $x$ 40) and micrographs were taken with the help of Celestron ${ }^{\circ}$ eyepiece digital camera (EC 3.0 MP,
China). Coronal sections of the hippocampus were observed in the treated rats and compared to the controls.

\section{Statistical Analyses}

The data were expressed as mean \pm SEM. Repeated measures ANOVA followed with Fisher's multiple comparisons post-hoc was carried out to find the mean differences in the escape latency, exploration, discrimination and novelty preference time between groups using Minitab 17 (LLC., U.K.) statistical package software. $P<0.05$ was considered statistically significant. All figures and charts were constructed using GraphPad Prism 8.

\section{RESULTS}

No mortality symptoms were observed in the first phase when the animals received 10, 100 and $1,000 \mathrm{mg} / \mathrm{kgbwt}$. However, muscarinic symptoms such as restlessness (hyperactivity), laboured breathing, piloerection, abdominal cramps, stooling (diarrhoea), and urination, were observed especially at the 1,000 $\mathrm{mg} / \mathrm{kgbwt}$. The symptoms later disappeared and the animals became calm, weak and quiet. During the second phase, the symptoms persisted with high intensity in all the groups treated with 1,600, 2,900 and 5,000mg/kgbwt. Neurotoxicity symptoms were observed but, no mortality was recorded even at the highest dose. The $D$. stramoniumfraction was therefore considered safe and $5000 \mathrm{mg} / \mathrm{kgbwt}$ was taken as the $L D_{50}$.

Figure 1 comparison for the test - phase in novel object recognition test experiment between the control and 200, 400, and 800 $\mathrm{mg} / \mathrm{kgbwt}$ adult treated Wistar rats' groups using two non-identical objects, familiar object (A) and non-familiar object (B) There was a significant difference in the exploration time between the group $[\mathrm{F}(3,40):=9.80, p=$ 0.003]. The control group spent statistically significant time $(p=0.031)$ exploring the unknown object (B) compared to the known object (A) The exploration time between the two objects for all the treated groups was, however, not significant $(p>0.05)$ : For the low dose treated group $p=0.191$, medium dose, $p=$ 0.406 and for the high dose, $p=0.071$ respectively. 


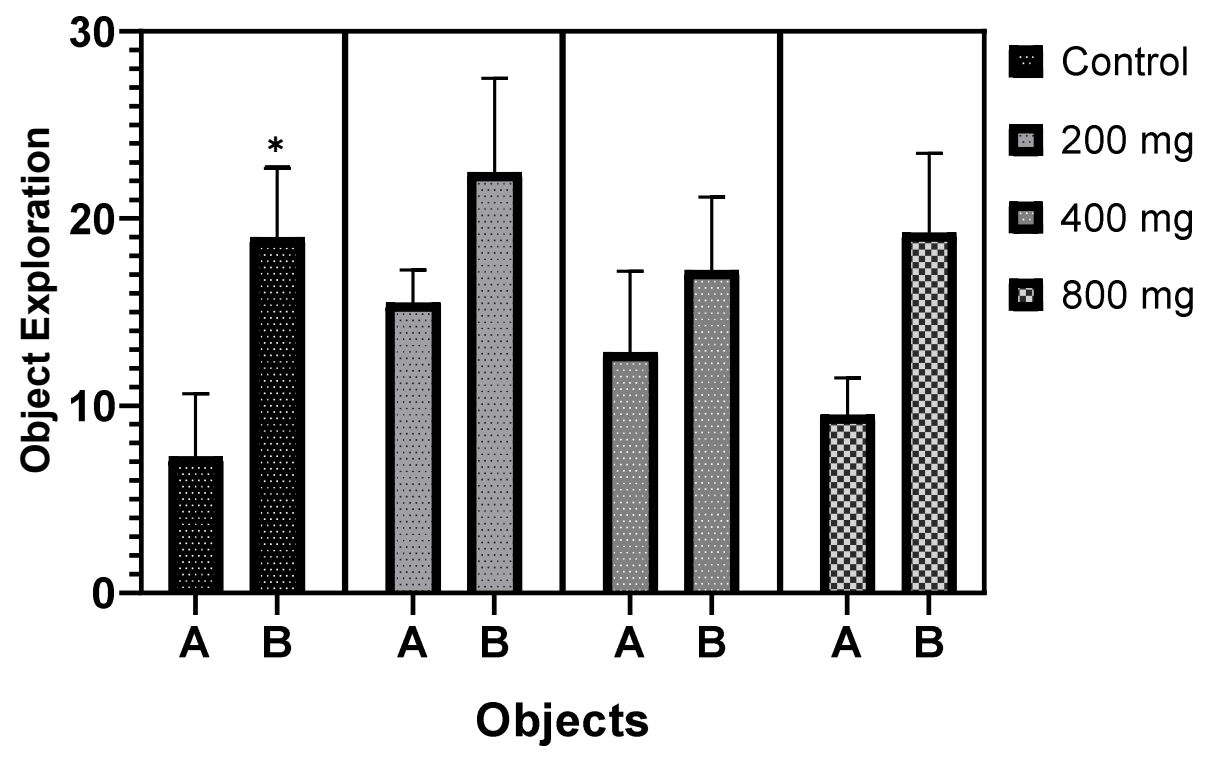

Figure 1. The test phase of Novel object recognition in Adult Wistar rats $(A=$ familiar object, $B=$ Novel object):

Figure 2 shows the trend of escape latencies using repeated-measures ANOVA with Fisher's pair-wise comparisons post-hoc test for the spatial learning and memory test between the control, 200, 400 and 800 $\mathrm{mg} / \mathrm{kg}$ bwthyoscyamine fraction treated adult Wistar rat groups. There was a statistically significant difference between the groups $[\mathrm{F}(3$, $120)=3.01, p=0.033]$ and between days [5 $(5,120)=14.80, p<0.001]$ for the group treated with $200 \mathrm{mg} / \mathrm{kgbwt}$. The post-hoc test shows that in the first three days of the five days training, control groups showed consistent shorter duration of escape latencies which were statistically not significant $(p>0.05)$ when compared to the treated groups in the same days. Conversely, the escape latencies of the fourth and fifth days among the treated groups were slightly shorter, however, not significant statistically $(p>0.05)$ when compared with their respective controls. On the sixth day which was the test - day, escape latency of the control was significantly lower statistically $(p=0.008)$ when compared to the treated groups. For the group treated with $400 \mathrm{mg} / \mathrm{kgbwt}$ also, a statistically significant difference between the groups $[\mathrm{F}(3$, $120)=3.01, p=0.033]$ and days $[5(5,120)=$
$14.80, p<0.001]$ was observed. There was a consistent flow pattern of escape latencies between the two groups with the controls taking the leads in the first five training days. Although the difference in the latency time was prominent in the fourth day, however, no statistically significant $(p=0.628)$ difference was observed between the groups. It took the treated group a longer duration in the sixth day to arrive the platform ( $p=0.023$ ) when compared to the control, hence statistically significant. Finally, the figure also showed a comparison of 800 $\mathrm{mg} / \mathrm{kgbwthyoscyamine}$ fraction treated adult Wistar rats. There was statistically significant difference between the treated groups $[F(3$, $120)=3.01, p=0.033]$ and between days [5 $(5,120)=14.80, p<0.001]$. The control group took lesser escape latency time during the first and third training days compared to the control. Although the difference in the escape latency time was prominent on the third day, however, no statistically significant difference $(p>0.05)$ was observed between the groups. The control group showed higher escape latency on the fifth day but lower and statistically significant escape time $(p=0.041)$ on the sixth day. 


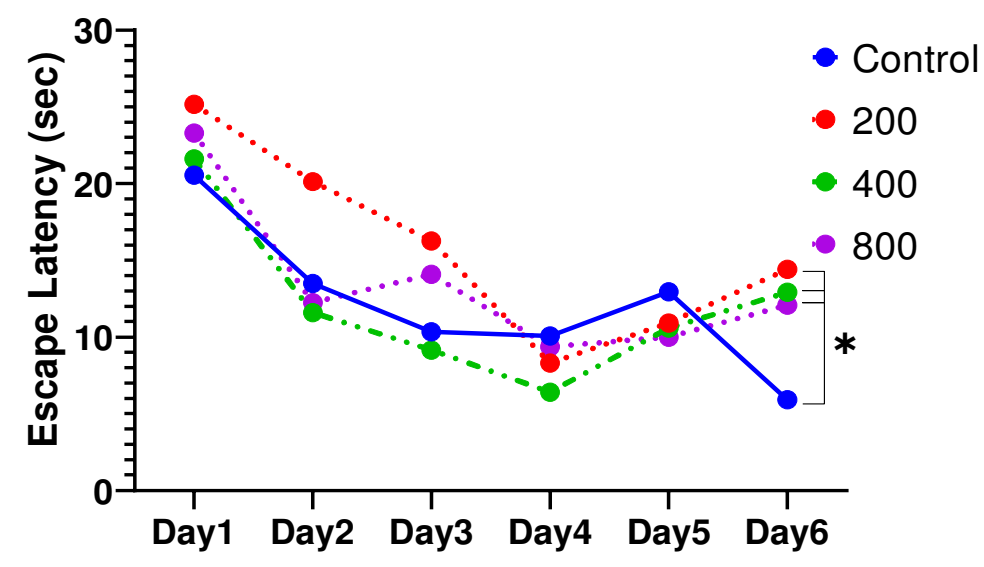

Figure 2. Morris water maze test in Wistar rats treated with hyoscyamine at adulthood

Plate 1 showed a photomicrograph of CA3 region of the hippocampus in control and treated groups of adult Wistar rats at $12^{\text {th }}$ week after being treated orally with an equivalent bodyweight of normal saline (a), 200 (b), 400 (c) and 800 (d) $\mathrm{mg} / \mathrm{kgbwt}$ of hyoscyamine fraction of D.stramonium respectively for three weeks, from PND $56-77$. Plate Ia showed normal histology of the CA3 region featuring SO, SR and PC in the region with traces of mossy fibres within the neuropil. In plate Ib, which received the least dose, scanty, hypochromic, pyknotic (black arrowheads) cytoplasmic vacuolation (black asterisk) and necrotic (black arrowheads) pyramidal cells were observed. The CA3 in plate Ic regions of the group treated with moderate-dose a scanty, hypochromic, cytoplasmic vacuolation (black asterisk) and necrotic (black arrowheads) cells. For the group that received the highest dose, plate Id, also scanty, hypochromic, hypertrophied pyramidal cells (black arrows): cytoplasmic vacuolation (black asterisk) and necrotic (black arrowheads) cells were also observed.

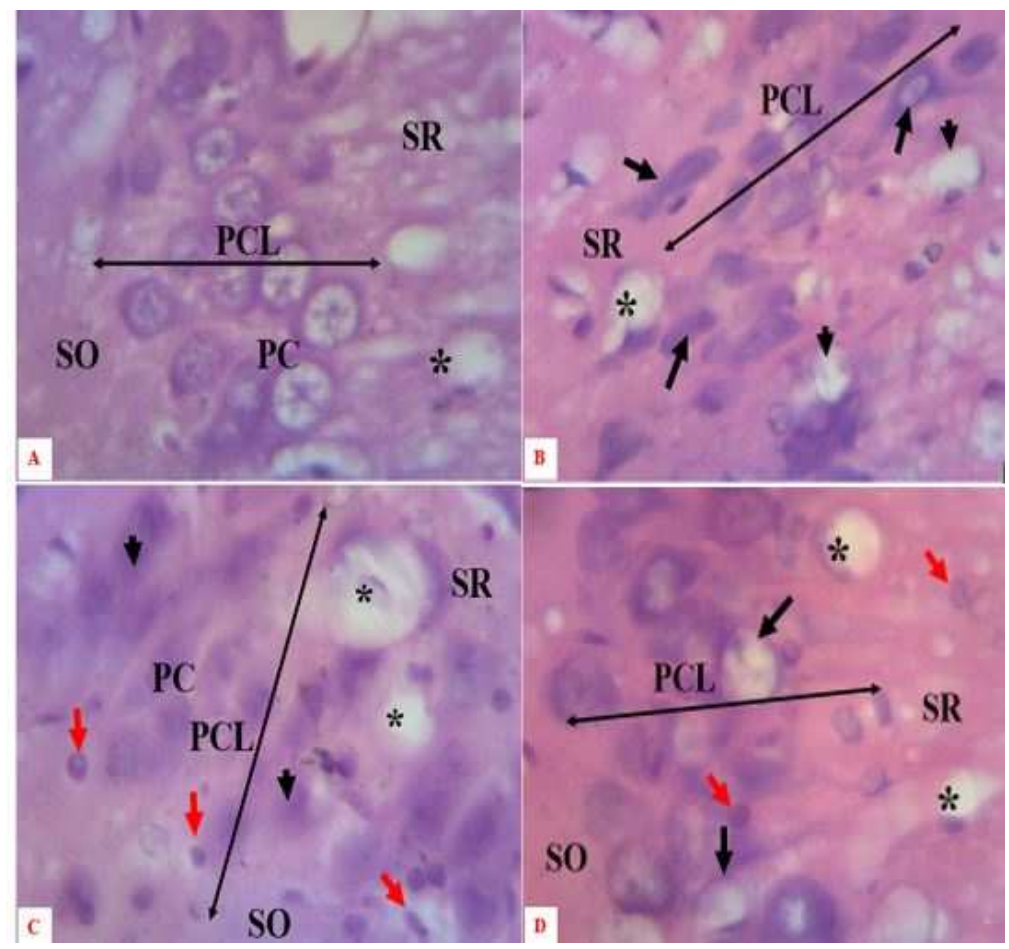

Plate 1. Photomicrographs of Cornu Ammonis (CA3) of the hippocampus in adult Wistar rat at $12^{\text {th }}$ week after being treated with an equivalent bodyweight of normal saline (A), 200 (B), 400 (C) and 800 (D) $\mathrm{mg} / \mathrm{kgbwt}$ hyoscyamine fraction of $D$. stramonium L. seeds from the PND $56-77$ (H\&E, $\mathrm{x} 400) . \mathbf{P C L}=$ pyramidal cell layer, $\mathbf{S O}=$ stratum oriens, $\mathbf{S R}=$ stratum radiatum,, $\mathbf{P C}=$ pyramidal cells, $*=$ cytoplasmic vacuolation. SLM $=$ stratum lacunosum moleculare $\rightarrow=$ necrotic neuronal cells, 4 = pyknotic neuronal cells, $\rightarrow$ = oligodendrocytes. 


\section{DISCUSSION}

The toxicity of Daturastramonium is attributed to present of tropane alkaloids obtainable in all its parts especially the seeds. The commonest alkaloids include; hyoscine, atropine, scopolamine and hyoscyamine (Arnett, 1995). Ingestion of hyoscyamine fraction resulted in both central and peripheral muscarinic symptoms in the rats fed with graded doses of the fraction. However, no mortality was recorded as a result of ingestion both during toxicity testing and experiment itself. In a related study by Babalolaet al. (2014) reported that the median toxic dose of $D$. stramoniumfed orally in dogs was at the safety margin as considered Centre for Disease Control (CDC) the United State of America, states. However, there was no published literature to make a comparison with regard to the present study in Wistar rats. Considering the foregoing it could be assumed that oral ingestion of $D$. stramonium seeds might equally have high safety margin in Wistar rats. The clinical symptoms observed might probably not to be unconnected with the anticholinergic properties of tropane alkaloids which competes and irreversibly inhibits acetylcholine on muscarinic receptors, thereby causing both central and peripheral nervous system manifestations (Hanna et al., 1992). The central nervous system features include restlessness (hyperactivity), laboured breathing and delirium, while the peripheral symptoms observed include breathing, piloerection, abdominal cramps, stooling (diarrhoea), and urination. Similar observations were reported in patients involved in D. stramoniumpoisoning (Ramirez et al., 1999).

The curent study observed a statistically significant difference in the exploration time across the groups when compared to the control except for the group that received the highest dose. Both discrimination index and novelty preference showed a statistically significant decrease in the affinity to the novel object in the treated group when compared to control, surprisingly in a slight J-shaped response curve. Also, a statistically significant decrease in the Morris water maze task was equally observed in the cognitive function test. This has indicated a memory loss, a neurodegenerative symptom similarly viewed (Langaet al., 2004; Schneider et al., 2007). Studies have shown that $D$. stramonium contains tropane alkaloids which induce hallucinations and metabolic disorder in rats (Abubakaret al., 2010; Damilareet al., 2010; Richard et al., 2011; Tijani et al., 2012) and also implicated in the disorders of hippocampal development in rats (Ishola and Adeniyi, 2013).
Atropine, tropane alkaloid of similar action was reported to cause a significant deficit in recognition memory in intraperitoneally treated rats when compared with the control from the novel object recognition result (Olawepoet al., 2017). This was also supported by the fact that D.stramonium has been documented to cause permanent short-term memory loss, and impairs learning because it contains a compound known as gamma-l-glutamyl-l-aspartate (SchmitzBourgeois et al., 1988). Studies have also reported impairment in short-term memory, disorientation, confusion, hallucinations, psychosis, agitated delirium, seizures, coma, respiratory failure and cardiovascular collapse (Alberto et al., 2001). following accidental poisoning or intentional ingestionof $D$.stramonium. The slight J-shaped response curve observed has indicated that ingestion of low-dose of hyoscyamine fraction of D.stramonium could equally impair memory as or even more than the higher dose repeatedly over time. This could be attributed to so many factors such as the presence of phenolic compounds (Nwekeet al., 2015), perfluorinated carboxylic acids (Mulkiewiczet al., 2007), mycotoxins (Wang et al., 2014), bacteriocins (Murado and Vázquez, 2010), antibiotics (Miglioreet al., 2013), herbicides (Nwekeet al., 2016), heavy metals (Shen et al., 2009) and ionic liquids (Wang et al., 2011): either as an individual or as mixtures. Similarly, the poor response in the higher dose observed could probably result from desensitization of the muscarinic receptors, thus leading to addiction.

We observe a relatively variable degrees of neuronal lesion ranging from neuronal hyperchromasia, pyknosis, necrosis, slight hypertrophy and cytoplasmic vacuolation when compared to the control group. This has indicated that oral ingestion of hyoscyamine fraction of $D$. stramonium has a profound toxic effect that could lead to neurodegeneration on the hippocampus of the Wistar rats. This was in line with Ekanemet al. (2016), which reported that oral ingestion of $D$. stramonium extract caused atrophy of the axons and fibres, vacuolation, cell necrosis and cell losses. Bihaqiet al. (2012) also observed neuronal loss, ghost cells, haemorrhage and vacuolated cytoplasm on treated rats that received daily intraperitoneal administration of scopolamine in the histology of the cerebral cortex examined under a light microscope. Although the cause of these changes is unknown, however, evidence can be supported by the fact that various mediators can contribute to excitotoxin action, which include the production of reactive oxygen 
BAJOPAS Volume 13 Number 2,December, 2020

intermediates, nitric oxide, p53 and cytokines which could lead to a series of cascading events leading to cell losses in the hippocampus (Coyle and Puttfarcken, 1993; Epstein et al., 1994; Ankarcronaet al., 1995; Morrison et al., 1996). D. stramonium tropane alkaloids all have a long duration of effect, cross the blood-brain barrier and have central anticholinergic effects (Baniaet al., 2004): which induce strong hypnosis and can also induce neuronal degeneration (Hughes and Clark, 1939).

\section{CONCLUSION}

In conclusion, oral ingestion of hyoscyamine fraction of $D$. stramonium at adulthood caused alteration in the histoarchitectural patterns of the cornuammonis (CA3) region of hippocampus neurons, which impaired cognitive learning and spatial memory. It is therefore recommended that repeated ingestion of hyoscyamine fraction of $D$. stramonium should be avoided.

\section{REFERENCES}

Abubakar, M., Suleiman, U., Frank, A. and Ukwani, A. (2010): Hallucinogenic Effects Of Aqueous Seeds Extract Of DaturaMetel In Rats. The Internet Journal Of Pharmacology, 9(1): doi: $10.5580 / 13 f d$

Alberto, K., Claudia, S., Ludmilla, K. and Arnon, B. (2001): Toxic Delirium due to Daturastramonium. Israel Medical Association Journal, 3, 538-539.

Al-Shaikh, A. and Sablay, Z. (2005): Hallucinogenic plant poisoning in children. Saudi Medical Journal, 26, 118-121.

Ankarcrona, M., Dypbukt, J., Bonfoco, E., Zhivotovsky, B., Orrenius, S., Lipton, S. and Nicotera, P. (1995): Glutamateinduced neuronal death: A succession of necrosis or apoptosis depending on mitochondrial function. Neuron, 15(4): 961-973. doi: 10.1016/08966273(95):90186-8

Arnett, A. (1995): Jimson Weed (Daturastramonium): Poisoning. Clinical Toxicology Review, 18, 1-6.

Arouko, H., Matray, D., Braganca, C., Mpaka, P., Chinello, L. and Castaing, F. (2003): Voluntary poisoning by ingestion of Daturastramonium. Another cause of hospitalisation in youth seeking strong sensations. Annual International Medicine Conference, 154, 46-50.

Babalola, S.A. (2014): Daturametel L: Analgesic or Hallucinogen? "Sharo" Perspective.Middle-East Journal of Scientific Research 21(6):993-97.

Bania, T., Chu, J., Bailes, D. and O'Neill, M. (2004): Jimson Weed Extract as a

\section{CONFLICT OF INTEREST}

The authors declared no conflict of interest.

\section{ACKNOWLEDGEMENTS}

We sincerely appreciate MallamKabiru, MallamSaiduBala-riti, Bashir Sulaiman and Late MallamSalihu of the Departments of Pharmacognosy, Pharmacology and Pharmaceutical Chemistry for the assistance rendered in the course of this research. We equally appreciate the staff of the Animal House, Department of Anatomy, Faculty of Basic Medical Sciences, College of Health Science, Bayero University Kano, Nigeria for the animal breeding. We also thank MrJigoDangudeYaro of histopathology unit of Ahmadu Bello University Teaching Hospital (ABUTH) for the slide preparation and interpretation.

Protective Agent in Severe Organophosphate Toxicity. Academic Emergency Medicine, 11(4): 335-338. doi: 10.1197/j.aem.2003.12.002

Başaran, Ş., Dündar, G. and Öğün, M. (2018): Daturastramonium Poisoning Case with Wernicke Aphasia-Like Symptoms: Case Report. Kocaeli Medical Journal, ス1): 83-86. doi: 10.5505/ktd.2018.36449

Benouadah, Z., Mahdeb, N. and Bouzidi, A. (2016): Evaluation of acute and subacute toxicity of alkaloids from Daturastramonium sp. in mice. International Journal PharmacognosyAndPhytochemistry Research, 8(11): 1759-1766.

Bihaqi, S., Singh, A. and Tiwari, M. (2012): Supplementation of Convolvulus pluricaulis attenuates scopolamineinduced increased tau and Amyloid precursor protein (A $\beta P P)$ : expression in rat brain. Indian Journal of Pharmacology, 44(5): 593. doi: 10.4103/0253-7613.100383

Bontoyan, W. (2010): Jimsonweed poison associated with homemade stewMaryland centres for disease control and prevention. Morbidity Mortality Weekly Report, 59(4): 102-103.

Boumba, A., Mitselou, A. and Vougiouklakis, T. (2005): Fatal poisoning from ingestion of Daturastramonium seeds. Veterinary And Human Toxicology, 46, 81-82.

Corkin, S. (1984): Lasting Consequences of Bilateral Medial Temporal Lobectomy: Clinical Course and Experimental Findings in H.M. Seminars In Neurology, 4(02): 249-259. doi: 10.1055/s-20081041556 
BAJOPAS Volume 13 Number 2,December, 2020

Coyle, J. and Puttfarcken, P. (1993): Oxidative stress, glutamate, and neurodegenerative disorders. Science, 262(5134): 689-695. doi: 10.1126/science.7901908

Damilare, A., Tijani, A. and Ghazal, O. (2010): Some effects of the aqueous leaf extract of Daturametel on the frontal cortex of adult Wistar rats. European Journal Of Anatomy, 14(2): 83-89.

Diker, D., Markovitz, D., Rothman, M. and Sendovski, U. (2007): Coma as a presenting sign of Daturastramonium seed tea poisoning. European Journal of Internal Medicine, 18(4): 336-338. doi: 10.1016/j.ejim.2006.09.035

Djilani, A., Legseir, B., Soulimani, R., Dicko, A. and Younos, C. (2006): New extraction technique for alkaloids. Journal of The Brazilian Chemical Society, 1入3): 518$520 . \quad$ doi: 10.1590/s010350532006000300013

Dubey, P. and Sanjeev, O. (2017): Acute Renal Failure: A Complication of Datura Poisoning. Journal Of Kidney, 03(03): doi: 10.4172/2472-1220.1000147

Ekanem, P., Ekanem, R. and Gaim, K. (2016): Histological Patterns of Neurodegeneration of Frontal Cortex Neurons in Daturastramonium Treated Wistar Rats. Journal Of Behavioral And Brain Science, 6(2): 85-92. doi: 10.4236/jbbs.2016.62009

Epstein, F., Lipton, S. and Rosenberg, P. (1994): Excitatory Amino Acids as a Final Common Pathway for Neurologic Disorders. New England Journal of Medicine, 330(9): 613-622. doi: 10.1056/nejm199403033300907

Ertekin, V., Selimoğlu, M. and Altinkaynak, S. (2005): A combination of unusual presentations of Daturastramonium intoxication in a child: Rhabdomyolysis and fulminant hepatitis. The Journal of Emergency Medicine, 28(2): 227-228. doi: 10.1016/j.jemermed.2004.11.006

Forrester, M. (2006): Jimsonweed (Daturastramonium): Exposures in Texas, 1998-2004. Journal Of Toxicology And Environmental Health, Part A, 69(19): 1757-1762. doi: $10.1080 / 15287390600631284$

Gilbert, P. and Brushfield, A. (2009): The role of the CA3 hippocampal subregion in spatial memory: A process-oriented behavioural assessment. Progress In Neuro-Psychopharmacology And Biological Psychiatry, 33(5): 774-781. doi: 10.1016/j.pnpbp.2009.03.037
Hanna, J., Schmidley, J. and Braselton, W. (1992): Datura Delirium. Clinical Neuropharmacology, 15(2), 109-113. doi: $\quad 10.1097 / 00002826-199204000$ 00004.

Hughes, J. and Clark, J. (1939): Stramonium Poisoning. Journal of the American Medical Association, 112(24): 2500. doi: 10.1001/jama.1939.02800240016005

Ishola, A. and Adeniyi, P. (2013): Retarded hippocampal development following prenatal exposure to ethanolic leaves extract of Daturametel in Wistar rats. Nigerian Medical Journal, 54(6), 411. doi: 10.4103/0300-1652.126299

Jonasson, M. and Afshari, R. (2016): Chronicle of Datura toxicity in 18th and 19th century. Asia Pacific Journal Of Medicine And Toxicology., 5, 4-10.

Joshi, B., Prakash, A. and Kalia, A. (2015): Hepatoprotective potential of antioxidant potent fraction from Urticadioica Linn. (whole plant): in $\mathrm{CCl} 4$ challenged rats. Toxicology Reports, 2, 1101-1110. doi: 10.1016/j.toxrep.2015.07.020

Joshi, B., Prakash, A. and Kalia, A. (2015): Hepatoprotective potential of antioxidant potent fraction from UrticadioicaLinn. (whole plant) in $\mathrm{CCl} 4$ challenged rats. Toxicology Reports, 2, 1101-1110. doi: 10.1016/j.toxrep.2015.07.020

Kamada, H., Okamura, N., Satake, M., Harada, H. and Shimomura, K. (1986):. Alkaloid production by hairy root cultures in Atropa belladonna. Plant Cell Reports, 5(4): 239-242.

Korkmaz, M., Bostancı, ., Onur, H. and Çağan, E. (2019): Daturastramonium poisoning: a case report and review of the literature. The European Research Journal. doi: 10.18621/eurj.392041

Kurzbaum, A., Simsolo, C., Kvasha, L. and Blum, A. (2001): Toxic delirium due to Daturastramonium. Israel Medical Association Journal, 3, 538-539.

Langa, K., Foster, N. and Larson, E. (2004): Mixed Dementia. Journal of American Medical Association, 292(23): 2901. doi: 10.1001/jama.292.23.2901

Lillie, R. and Fullmer, H. (1976): Histopathologic technic and practical histochemistry. New York [usw.], Düsseldorf: Mc-GrawHill.

Lorke, D. (1983): A new approach to practical acute toxicity testing. Archives of Toxicology, 54(4), 275-287. doi: 10.1007/bf01234480

Migliore, L., Rotini, A. and Thaller, M. (2013): Low Doses of Tetracycline Trigger the $\mathrm{E}$. 
BAJOPAS Volume 13 Number 2,December, 2020 coli Growth: A Case of Hormetic Response. Dose-Response, 11(4): 1. doi: $\quad 10.2203 /$ dose-response.13002.migliore

Milner, B., Squire, L. and Kandel, E. (1998): Cognitive Neuroscience and the Study of Memory. Neuron, 20(3): 445-468. doi: 10.1016/s0896-6273(00):80987-3

Miraldi, E., Masti, A., Ferri, S. and BarniComparini, I. (2001): Distribution of hyoscyamine and scopolamine in Daturastramonium. Fitoterapia, 72(6): 644-648. doi: 10.1016/s0367326x(01):00291-x

Mishra, D. (2018): Daturastramonium (common name: jimson weed): medicinal uses, side effects and benefits. World Journal Of Pharmaceutical Research, 入12): 1011-1019.

Montcriol, A., Kenane, N., Delort, G., Asencio, Y. and Palmier, B. (2007): Intoxication volontaire par Daturastramonium: une cause de mydriase mal connue. AnnalesFrançaisesD'anesthésie Et De Réanimation, 26(9): 810-813. doi: 10.1016/j.annfar.2007.04.006

Morris, R. (1984): Developments of a watermaze procedure for studying spatial learning in the rat. Journal of Neuroscience Methods, 11(1), 47-60. doi: 10.1016/0165-0270(84)90007-4

Morrison, R., Wenzel, H., Kinoshita, Y., Robbins, C., Donehower, L. and Schwartzkroin, P. (1996): Loss of the p53 tumour suppressor gene protects neurons from kainate-induced cell death. The Journal of Neuroscience, 16(4): 1337-1345. doi: 10.1523/jneurosci.16-04-01337.1996

Mueser, K., Drake, R. and Wallach, M. (1998): Dual diagnosis: A review of etiological theories. Addictive Behaviors, 23(6): 717-734. doi: 10.1016/s03064603(98):00073-2

Mulkiewicz, E., Jastorff, B., Składanowski, A., Kleszczyński, K. and Stepnowski, P. (2007): Evaluation of the acute toxicity of perfluorinated carboxylic acids using eukaryotic cell lines, bacteria and enzymatic assays. Environmental Toxicology And Pharmacology, 23(3): 279-285. doi: 10.1016/j.etap.2006.11.002

Murado, M. and Vázquez, J. (2010): Biphasic toxicodynamic features of some antimicrobial agents on microbial growth: a dynamic mathematical model and its implications on hormesis. $B M C$ Microbiology, 10(1): 220. doi: $10.1186 / 1471-2180-10-220$
Nweke, C., Ike, C. and Ibegbulem, C. (2016): Toxicity of quaternary mixtures of phenolic compounds and formulated glyphosate to microbial community of river water. Ecotoxicology And Environmental Contamination, 11(1): 63-71. doi: 10.5132/eec.2016.01.09

Nweke, C., Orji, J. and Ahumibe, N. (2015): Prediction of phenolic compound and formulated glyphosate toxicity in binary mixtures using Rhizobium species dehydrogenase activity. Advanced Life Science, 5(2): $27-38$.

Oberndorfer, S. (2002): Coma with focal neurological signs caused by Daturastramonium intoxication in a young man. Journal Of Neurology, Neurosurgery and Psychiatry, 73(4): 458-a-459. doi: 10.1136/jnnp.73.4.458a

Oberndorfer, S., Grisold, W., Hinterholzer, G. and Rosner, M. (2002). Coma with focal neurological signs caused by Daturastramonium intoxication in a young man. Journal of Neurology, Neurosurgery \& Psychiatry, 73(4), 458a-459. doi: 10.1136/jnnp.73.4.458-a

Olawepo, A., Ishola, A., Ajao, M., Olayemi, O. and Olayaki, L. (2018): Atropine exposure in adolescence predispose to adult memory loss in Wistar rats. International Journal Of Biological And Chemical Sciences, 11(5): 1937. doi: 10.4314/ijbcs.v11i5.1

Preissel, U. and Hans-George, P. (2002): Brugmansia and Datura: Angel's Trumpets and Thorn Apples Buffalo (pp. 106-129): New York: Firefly Books.

Qing, H., He, G., Ly, P., Fox, C., Staufenbiel, M. and Cai, F. et al. (2008): Valproic acid inhibits $A \beta$ production, neuritic plaque formation, and behavioural deficits in Alzheimer's disease mouse models. Journal of Experimental Medicine, 205(12): 2781-2789. doi: 10.1084/jem.20081588

Ramirez, M., Rivera, E. and Ereu, C. (1999): Fifteen cases of atropine poisoning after honey ingestion. Veterinary and Human Toxicology, 41, 1920.

Richard, A., Asim, T., Samuel, M., Michael, S., John, T., Michael, H. and John, D. (2011): Tropane Alkaloid Poisoning Clinical Presentation: History, Physical Examination. Retrieved 25 August 2020, from https://emedicine.medscape.com/article /816657-clinical 
BAJOPAS Volume 13 Number 2,December, 2020

Roblot, F., Montaz, L., Delcoustal, M., Gaboriau, E., Chavagnat, J. and Morichaud, G. et al. (1995): Intoxication par Daturastramonium: Le diagnostic estclinique, traitementestsymptomatique. La Revue De Médecine Interne, 16(3): 187-190. doi: 10.1016/0248-8663(96):80689-8

Schmitz-Bourgeois, M., Amiri, I., Reinbolt, J., Boulanger, Y. and Ungerer, A. (1988): Isolation and structure of a pseudopeptide $\quad$-I-glutamyl-I-aspartic acid from Daturastramonium that impairs learning retention in mice. Biochimie, 70(9): 1179-1184. doi: 10.1016/0300-9084(88):90183-6

Schneider, J., Arvanitakis, Z., Bang, W. and Bennett, D. (2007): Mixed brain pathologies account for most dementia cases in community-dwelling older persons. Neurology, 69(24): 2197-2204. doi:

10.1212/01.wnl.0000271090.28148.24

Shen, K., Shen, C., Lu, Y., Tang, X., Zhang, C. and Chen, X. et al. (2009): Hormesis response of marine and freshwater luminescent bacteria to metal exposure. Biological Research, 42(2): doi: 10.4067/s0716-97602009000200006

Soni, P., Siddiqui, A., Dwivedi, J. and Soni, V. (2012): Pharmacological properties of Daturastramonium L. as a potential medicinal tree: An overview. Asian Pacific Journal Of Tropical Biomedicine, 2(12): 1002-1008. doi: $10.1016 / \mathrm{s} 2221-$ 1691(13):60014-3

Squire, L. and Alvarez, P. (1995): Retrograde amnesia and memory consolidation: a neurobiological perspective. Current Opinion In Neurobiology, 5(2): 169-177. doi: 10.1016/0959-4388(95):80023-9

Steenkamp, P., Harding, N., van Heerden, F. and van Wyk, B. (2004): Fatal Datura poisoning: identification of atropine and scopolamine by high-performance liquid chromatography/photodiode array/mass spectrometry. Forensic Science International, 145(1): 31-39. doi: 10.1016/j.forsciint.2004.03.011

Tijani, A., Adekomi, D. and Ibiyeye, Y. (2012): Histological study of the effects of oral administration of $D$. metel on the visual system of male Wistar rat. Scientific Journal Of Biological Sciences, 1(1): 11.

Trancă, S., Szabo, R. and Cocis, M. (2017): Acute poisoning due to ingestion of Daturastramonium - a case report. Romanian Journal OfAnaesthesiaAnd Intensive Care, 24(1): doi: 10.21454/rjaic.7518.241.szb

Uddin, F., Hossain, A., Das, R., Rahman, A., Akanda, R. and Islam, S. (2017): Evaluation of toxic effects of Datura Leaves (Daturastramonium): in the rat. International Journal Of Agriculture And Environmental Research, 3(4): 34863497.

Vearrier, D. and Greenberg, M. (2010): Anticholinergic delirium following Daturastramonium ingestion: Implications for the Internet age. Journal Of Emergencies, Trauma, And Shock, 3(3): 303. doi: 10.4103/09742700.66565

Wang, H., Wang, J., Zheng, B., Li, S., Zhang, Y., Li, F. and Zheng, N. (2014): Cytotoxicity induced by ochratoxin $A$, zearalenone, and a-zearalenol: Effects of individual and combined treatment. Food And Chemical Toxicology, 71, 217-224. doi: 10.1016/j.fct.2014.05.032

Wang, L., Liu, S., Yuan, J. and Liu, H. (2011): Remarkable hormesis induced by 1 ethyl-3-methyl imidazoliumtetrafluoroborate on Vibrio qinghaiensis sp.-Q67. Chemosphere, 84(10): 1440-1445. doi: 10.1016/j.chemosphere.2011.04.049 
BAJOPAS Volume 13 Number 2,December, 2020

\section{APPENDIX - I}

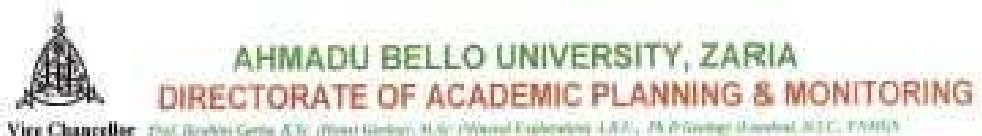

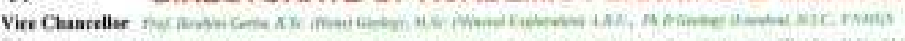

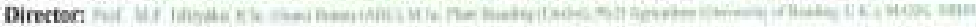

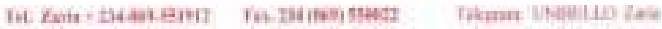

noml andfataintiry

Appl No.: ABUCAUC/2018/Human AnaComy/042

$3^{\text {rd }}$ October, 201B

Approval No: ABUCAJC/2018,042

Dr. 5. A. Muso

Departinent of Human Ariatomy,

Faculty of Basic Medical Sciences,

College of Health Sciences,

Ahmadu Bello Universty,

Zaria.

Six,

APPROVAL OF RESEARCH STUDY EVALUATION OF INGESTION OF HYOSCYAMINE FRACTIONATE OF DATURA STRAMONIUM SEEDS ON CEREBRUM DEVELOPMENT IN WISTAR RATS (RATTUS NORVEGICUSY)

This is ta convey the approval of the ABUCALC to you for the aforestated study domicled in the Depertment of Human Aratomy. The approval is predicated on the assumption that you shall maintain and care for the Experimental Animals as approved after the visitation of the Comimittee.

Monitoring of the Research by spoc checks, inwitations or any other means the Committre deems fit shail be undertaken at the convenience of the Committee.

This apgroval cas and shail be revoked should a significank breach in the terns and condition of the approval occur. It is hence your resporsibity to ensure that the agraed terms are maintained to the end of the study.

The said approval shall be posted on the ABUCAUC Page on the University's website. Note upon compietion of the research, ethical clearance certificate will be ssued.

Sिसीlly

U.D. Abdultahi

For: Chaiman, ABUCAUC.

C. Director, DAPM

Director, IC BICT

Provost, College of Heaith 5 ciences

Dean, Faculty of Basic Medical Suiences.

HOO, Human Anatomy,

Prof. Alyu Mohammed 